\title{
TOPICALITY OF IMPLEMENTATION OF MOBILE MEDICAL APPLICATIONS WITHIN THE FRAMEWORK OF ELECTRONIC HEALTH IN UKRAINE: THE EXPERIENCE OF LEADING COUNTRIES OF THE WORLD
}

\author{
Alla Nemchenko \\ Department of Organization and Economy of Pharmacy ${ }^{l}$ \\ Viktoriya Nazarkina \\ Department of Organization and Economy of Pharmacy ${ }^{l}$ \\ Yuliia Kurylenko \\ Department of Organization and Economy of Pharmacy ${ }^{l}$ \\ Nataliia Teterych \\ Department of Organization and Economy of Pharmacy ${ }^{l}$ \\ Lyubov Tereschenko \\ Department of Social Pharmacy ${ }^{l}$ \\ ${ }^{1}$ National University of Pharmacy \\ 53 Pushkinska str., Kharkiv, Ukraine, 61002
}

\begin{abstract}
Today, in the field of healthcare of the leading countries of the world there is a technological breakthrough due to the use of modern electronic systems. Thanks to the use of medical electronic technologies, it is possible to improve the quality of medical and pharmaceutical care for all segments of the population. The eHealth system provides opportunities for direct participation of patients in their health, which involves organization of a healthy lifestyle and disease prevention.

The aim of the study was to analyze the experience of implementation of mobile medical applications and electronic medical systems within eHealth in the healthcare systems of the leading countries of the world and Ukraine.

Materials and Methods. Ministry of Health of Ukraine, FDA, WHO, NHS, ABI Research and other open information databases and statistical agencies were used in the work. The analytical, comparative and generalization of scientific information methods were chosen for the research.

Results and Discussion. Modern reformation and further development of the healthcare system of Ukraine provides for the introduction of not only government programs of reimbursement, but also the introduction of electronic information systems, mobile applications for medical, pharmaceutical workers and patients at all stages of medical and pharmaceutical care. The integrated implementation of eHealth determines availability of the necessary healthcare management information system, which should have the following components: registers of medical institutions, services, doctors, patients, diagnosis coding system and electronic medical documentation (electronic medical records and prescriptions). Currently, 1472 medical institutions, 24506 doctors and 21068249 patients have joined eHealth in Ukraine.

Conclusions. It has been determined that information electronic technologies allow not only to reduce government spending on the healthcare, but also to achieve a reduction in the number of errors in prescriptions, visits to doctors without the necessary needs and decrease the total number of deaths. The introduction of electronic technologies, in particular mobile applications for the national healthcare system in Ukraine should be controlled by state authorities and independent international organizations on the control and development of information electronic systems.
\end{abstract}

Keywords: information technology, healthcare, electronic system.

DOI: $10.21303 / 2504-5679.2019 .00974$

\section{Introduction}

The current reform of the national healthcare system (NHS) is aimed at Ukraine's aspiration to join the European community. One of the main features of each developed European country is 
the appropriate level of NHS, which key features are the high level of medical and pharmaceutical services. It is known that modern trends in the development of NHS in the leading countries of the world are electronic technologies - mobile and electronic medical systems, especially electronic health system (eHealth), which rapid spread and use open up new and innovative means for improving the provision of medical and pharmaceutical care. In addition, thanks to modern electronic technologies, in particular online training, it is possible to have the increased access of the population in middle-and low-income countries to first aid training [1].

\section{Aim of the research}

According to the forecasts of the RAND Institute the large-scale distribution of eHealth will determine reduction of the healthcare costs by 142-371 billion USD each year [2]. Therefore, the aim of our study was to analyze the experience of implementation of mobile medical applications and electronic medical systems within eHealth in the healthcare systems of the leading countries of the world and Ukraine.

\section{Materials and methods}

Materials of the Ministry of Health of Ukraine, FDA, WHO, NHS, ABI Research and other open information databases and statistical agencies were used in the work [3-6]. The analytical, comparative and generalization of scientific information methods were chosen for the research.

\section{Result}

Low solvency of citizens in low- and middle-income countries leads to low availability of treatment of the most common diseases and deterioration of the epidemiological situation in these countries. Ukraine is not an exception; its current state of the healthcare development does not meet the needs of the majority of citizens. In this regard, NHS of Ukraine has taken a tack of development for the introduction of similar systems in the leading countries of the world, which governments are actively implementing the national programs to improve medical and pharmaceutical care and increase the availability of drugs for all segments of the population. For example, the "Available medicines" program was introduced by the Cabinet of Ministers of Ukraine in 2017, and with the support of Management Sciences for Health (MSH) from 1.09.2017 the country launched the project "Safe, available and effective medicines for the Ukrainians" (SAFEMed) [7, 8]. The aim of this project is to improve and optimize the functioning of the financing mechanisms of NHS. At the same time, the introduction of eHealth into NHS of Ukraine is hampered by limited budget funding and the absence of the rational development concept. In addition, the issue of the introduction of electronic information technologies in the healthcare, in particular mobile applications for use by medical and pharmaceutical specialists, as well as patients, remains unsolved, and taking into account the foreign experience such mobile applications have a huge demand [1]. It should be noted that eHealth involves the use of mobile devices in the process of collecting medical information about patients and transferring it to doctors.

In connection with the above, the study of the foreign experience in application of separate elements of eHealth on the example of some developed countries is rather relevant for NHS of Ukraine.

According to the estimates of the Commonwealth of Nations NHS fund, the United Kingdom now has the most effective NHS due to large-scale and effective use of information technologies in this area. Under the UK law, general practitioners (family doctors) are allowed to send information messages regarding drug prescriptions from the hospital post office to the pharmacy. This has led to the fact that the process of receipt of an electronic prescription in pharmacies has become more effective and convenient for both patients and pharmacists. In addition, the results of studies by experts of Commonwealth of Nations showed that in the UK, USA and Switzerland the number of errors in electronic prescriptions decreased by $60 \%$. At the same time, the introduction of information mobile systems in these countries reduced the overall mortality rate by $45 \%$, from emergency events by $20 \%$, the number of visits to medical professionals by subject-related reasons decreased by $14 \%$, tariff costs decreased by $8 \%$, more than $50 \%$ of the population began to use Internet resources to communicate with the doctor $[9,10]$. 
As it was mentioned, recently mobile applications in medicine, involving the use of mobile devices in the process of collecting medical information about patients and transferring it to doctors, as well as monitoring (in real time) the vital functions of the patient's body and direct remote aid through special mobile devices, are in great demand.

According to the data of ABI Research analytical company, it has been found that by 2019 the number of users of medical mobile applications will increase to 500 million people. Moreover, the volume of the market of mobile applications in medicine in 2017 increased almost 11 times compared to 2013. It should be noted that the first place by the number of downloads are applications with reference books of medicines $(23.7 \%)$, the second place is occupied by applications with physical exercises $(20.2 \%)$, the third one - applications that help to track the health status (12.9\%), and the fourth place - applications for disease prevention (10.1\%) [9]. According to the WHO data various types of services are implemented within the framework of mobile medicine, the most common of them are shown in Fig. 1.

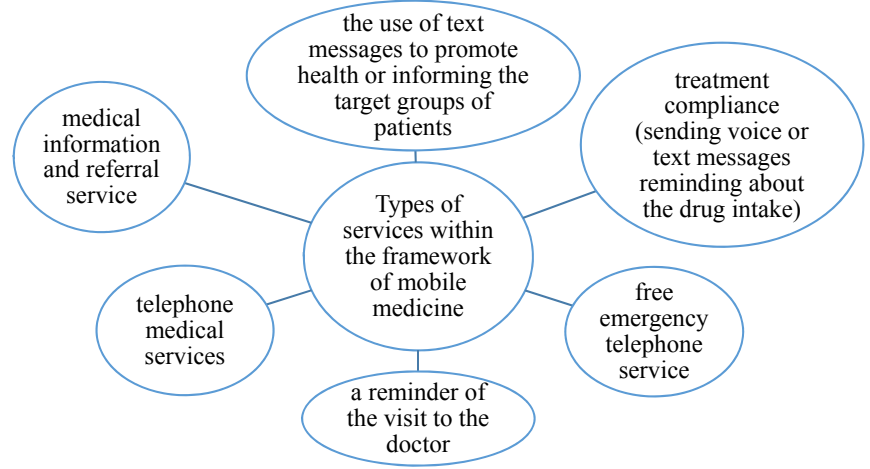

Fig. 1. The most common types of services within the framework of mobile medicine (the WHO data)

Therefore, mobile medicine works to raise awareness of the population, for example concerning topical issues of healthcare. It should be noted that according to the KPCB forecasts the world market of mobile medical applications would reach 102.43 billion USD by 2022 . Today, the largest market of medical mobile applications is the United States. Potential markets of mobile applications in healthcare are projected to grow at maximum speed over the next five years. This concerns the Asia-Pacific region, Latin America and Europe [11-15].

The characteristics of the ranking of the top 15 medical mobile applications in popularity having a direct connection with the existing NHS are presented in Table 1. According to this Table 1, it has been found that $73 \%$ of mobile applications are partially paid and $13 \%$ are fully paid and free, respectively. Conventionally, all applications that are listed in the Table $\mathbf{1}$ can be divided into applications for doctors; patient applications; doctor and patient collaboration applications. A brief description of the applications is given below.

Applications such as Medscape, Epocrates, Read by QxMD, UpToDate, Isabel, Dyna Med Mobile are similar to each other and represent an encyclopedia on medical information, they have the same interface and principle of operation [16-18]. These applications contain information about various diseases and their treatment methods [19-21].

NEJM This Week and Fig. 1 Medical Images mobile applications are with the same direction of work - they help doctors exchange medical images of the patient for consultation or diagnosis while maintaining confidentiality $[22,23]$.

Applications Virtual Practice for Doctors, My Chart, and iPharmacy designed specifically for doctor and patient collaboration. They could be used in case you do not get to the doctor or do not receive the necessary clarifications regarding medication [24, 25]. The uniqueness of the doctor-patient applications creates conditions remotely and always in touch, as well as more detailed personal consultation with the patient [26]. 
It is worth noting that such mobile applications as Cardio Smart, Calculate by QxMD, which are created specifically for the doctor to work with patients suffering from cardiovascular diseases. These diseases occupy a leading place in the world in the number of prevalence among the working-age population. Therefore, there is no doubt about the relevance of creating applications for this pathology. Applications 1 help both doctors and patients to understand what happens to the vessels and the heart in various types of pathologies of the cardiovascular system [27, 28].

The mobile app Doximity deserves special attention. This application is one of the largest networks of interconnected doctors of various specialties in the United States. This is very convenient as you can quickly respond to questions from colleagues on the formulation of a diagnosis or to have the opinion of several experts [29].

Goo Patient created for patients who monitor their health. Thanks to the work with the application, it becomes possible to upload your analyzes and have them at hand always in dynamics [30].

Thus, the positive experience of the implementation of mobile applications within eHealth in the leading countries of the world provides NHS with tools for the effective and rational use of medical and pharmaceutical resources of the sector and the high-quality medical and pharmaceutical care to patients.

Now there is also a tendency to the introduction of information electronic systems in Ukraine. Thus, since 2008 on the initiative of the Ministry of Health of Ukraine there was an attempt to introduce an electronic medical passport of the patient and the all-Ukrainian electronic register of patients, but only in 2018, as part of the reform of NHS, the eHealth project was launched, the total cost of its development amounted to 400 thousand USD. The aim of eHealth was to optimize provision of medical care to patients and improve the work of doctors with the involvement of electronic healthcare, as well as monitoring the rationality of the use of budgetary funds [31-33].

It should be noted that the effectiveness of eHealth implementation requires availability of the appropriate healthcare management information system, which has the following components: registers of medical institutions, services, doctors, patients, diagnosis coding system and electronic medical documentation (electronic medical records), in particular electronic prescriptions.

Today one needs to choose one of 14 available medical information systems to work with eHealth: Helsi, MIC EMCiMED, Doctor Elex, MEDSTAR, MEDICS, Polyclinic without queues, MedAir, MedCard Plus, Askep.net, Health24, nHealth, UASMART, Medinfoservice, MIS "Kashtan". Currently, in Ukraine 1472 medical institutions, 24506 doctors and 21068249 patients joined eHealth. The largest number of institutions participating in the project was in the Lviv region 140 institutions (9.51\% of the total number of participating institutions), the Dnipropetrovsk region was in the second position- 94 (6.38\%) in the third position was Kyiv - 90 (6.11\%) and the fourth was the Kharkiv region - 87 (5.91\%) institutions, respectively. At the same time, the smallest number of participating institutions was in the Luhansk region- 19 (1.29\%).

The largest number of doctors who took part in the project was observed in the Dnipropetrovsk region - 1924 (7.85\% of the total number of participating doctors), in the Kharkiv region 1771 (7.22 \%), in Kyiv - 1731 (7.06 \%), and in the fourth position there was the Lviv region - 1668 $(6.80 \%)$ doctors, respectively. By the number of patients who signed a contract (declaration) with the hospital and the family doctor the leader was the Dnipropetrovsk region - 1779743 (8.44 \% of the total number of declarations), the Kharkiv region was in the second place - $1602772(7.60 \%)$ the Lviv region was third - 1459589 (6.92 \%) and in the fourth position was Kyiv - 1284785 (6.09 \%) declarations, respectively.

It should be noted, that most healthcare institutions are not in a hurry with the introduction of medical information systems required for effective participation in the abovementioned project. It may be connected with the unwillingness of health professionals to use electronic information systems due to the age of specialists, their inability or unwillingness to master the tools of modern information globalization.

Therefore, currently eHealth is the initial link in creating the national information electronic system of the healthcare. The next step in the reform of NHS should be distribution of mobile medical applications that will interact with the electronic information system. The characteristics of the basic principles of mobile medical applications are presented in Fig. 2. 
Table 1

The top 15 mobile medical applications for doctors, pharmacists and patients

\begin{tabular}{ll}
$\begin{array}{l}\text { Name of a medical } \\
\text { mobile application }\end{array}$ & Characteristics \\
\hline
\end{tabular}

Medscape

Multi-purpose medical reference book comprising original articles on various subjects, news from the

Epocrates It is one of the most informative resources for both physicians and consumers (free)

free, additional information is paid)

It allows you to read and download research results, journats and articles from a variety of sources (open Read by QxMD access journals, Pubmed and documents from relevant institutions) "Read" is a free application, but some journals and Pubmed may require a subscription

UpToDate

Medical reference book (the program is free, but access to information provides for a subscription to the database - 499 USD for a year)

Doximity

The largest social network for doctors in the United States (about $40 \%$ of medical professionals are users of this program). With a mobile phone and web platform, doctors can use the Doximity functionality to securely share Health Insurance Portability and Accountability Act data. Downloading the application is free

Isabel

The Isabel database has more than 6 thousand reports about diseases and symptoms, and it gives the possibility to specify results by age, sex of the patient, etc. To use the application the online access is required (it is free, but to use all of the functions you need to purchase a paid subscription)

Application for doctors practicing in cardiology, oncology and obstetrics. "Calculate" turns authoritative scientific medical research into practical tools for diagnosis, selection of doses of drugs, management of treatment, etc.

Virtual Practice for It allows the doctor to be in contact with the patient outside work (remote control of the patient and the Doctors

NEJM This Week ability to answer text questions)

It has access to the latest articles, allows you to view images of various medical pathologies, listen and see audio and video reviews of articles

Figure 1 Medical Images

It allows to view and share medical images with other professionals. The application ensures the privacy of the patient by using an automatic blocking of the person and eliminating the identifying information

My Chart

Dyna Med Mobile It is designed for individual use by patients. MyChart creates a direct communication between patients and healthcare professionals

It includes medical resources, information about places of providing medical care, reviews of more than 3,400 various topics (it costs 395 USD a year for a medical practitioner)

iPharmacy

It is a tool for patients and doctors that helps to find the prescribed drugs at the lowest price and has an electronic discount card

It allows to create the own electronic medical card, store the results of examinations (MRI, ultrasound),

Goo Patient copies of insurance, prescriptions, etc. The paid version allows you to register an account for several family members

Cardio Smart

It was created to discuss cardiovascular disease with patients. The doctor will be able to demonstrate to the patient exactly what happens to the heart muscle during a myocardial infarction or describe the process of coronary angiography, etc.

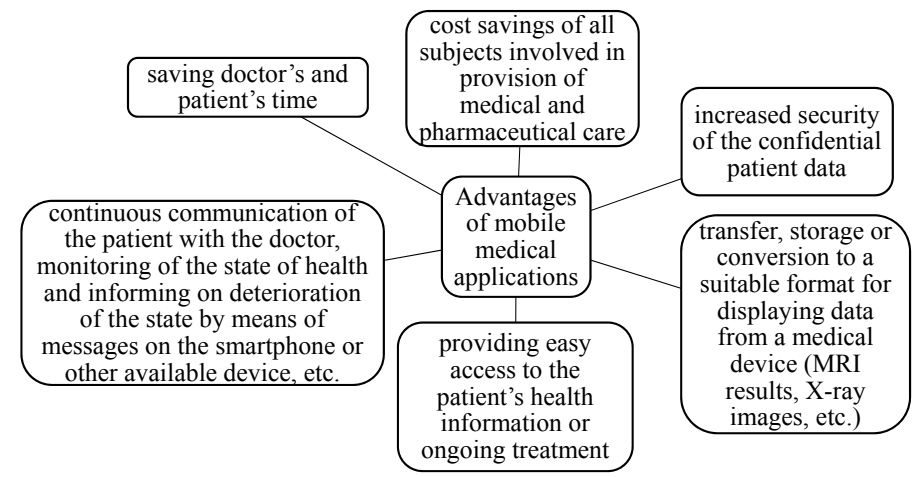

Fig. 2. The characteristics of the basic principles of mobile medical applications 


\section{Discussion}

When developing and introducing mobile medical applications in NHS, the Guidelines to mobile medical applications for professionals in the field of industry and food and medicines released by the FDA (USA) should be taken into account. This document explains that the agency monitors mobile medical applications that pose a greater risk to patients if they do not work properly, as well as applications that cause smartphones or other mobile platforms to affect the functionality or performance of traditional medical devices.

Currently, this Guidelines is a basic tool that developers can use to determine the extent to which FDA will regulate the application. The Guidelines defines a "mobile medical application" to refer to a mobile application or is intended to be used as an accessory to a regulated medical device [34-36].

Today there are 286 applications approved by FDA [37-39]. However, it should be noted that medical devices, including mobile applications, are classified into three classes depending on their risk profile:

- class I (overall control, low risk);

- class II (special and general control);

- class III (pre-approval, high risk).

Therefore, the introduction of mobile applications for NHS in Ukraine should be controlled by state authorities and independent international organizations dealing with the control and development of information electronic systems.

It should be noted some aspects, both positive and negative, from the introduction of mobile applications that affect the efficiency of the medical and pharmaceutical care to patients. The paper Ross, J et al., provides an overview of the factors that influence the implementation of e-health. According to the review, it was found that e-health is certainly progress and an impetus in the development of the entire patient care system, but there are also negative consequences of such an introduction that should also be addressed [41]. The work by Ludwick D. reviewed the results of the introduction of electronic medical records of patients in the health care system. It was revealed that, by the example of implementation in 7 countries, there is a problem of responsibility for the personal data of patients and, in general, the problem of confidentiality of all data existing in hospitals [42]. For example, in the study, the authors Liang X. et al., evaluated the impact of mobile phone intervention on the glycemic control in diabetes. It was found that intervention with a mobile phone led to a statistically significant improvement in glycemic control in patients with type 2 diabetes [43].

The author Boulos M. N. K. et al., presents an analysis of the impact of mobile phones and diligence on the development of health care and society as a whole. It has been found that smartphones are useful for medicine and health-related professions, because they are mobile, portable, easy to use and can be used on the road [44]. In the study "The impact of mobile handheld technology on hospital physicians" work practices and patient care: a systematic review, the authors concluded that the use of mobile applications demonstrates advantages in conditions where time is a critical factor, and quick response is decisive [45]. The author C. Free et al., found that the impact of mobile applications on the provision of medical and pharmaceutical care has shown positive results. This is due to the simplicity and efficiency of working with mobile applications [46].

According to the introduction of mobile health in all countries, should be carried out with the help of specialists. To this end, the mHealth Knowledge platform was created that connects healthcare professionals around the world - with people, products and ideas that are needed for effective work $[47,48]$. To keep track of new technologies in the field of mobile healthcare, the WHO released a collection of Compendium of new and emerging technologies aimed at solving global healthcare problems. This compilation was created as a neutral platform for technologies that can be used in conditions of limited resources. To this end, research2guidance has launched the digital health care market research program mHealth App Developer Economics since 2010 [49, 50].

Summing up at the same time, it is necessary to remember and take into account the relevant risks that may arise in the process of using mobile applications or electronic information systems, for example, incorrect interpretation of their data by patients, incorrect diagnosis and further drug 
use. Those inadequate self-medication or risks associated with the leakage of confidential patient data, etc. $[51,52]$.

\section{Conclusion}

The results of the study suggest that the introduction of mobile medicine in NHS will not only expand the access to medical and pharmaceutical care and health information, but will also strengthen the ability to diagnose, monitor and track diseases in a timely manner. Moreover, mobile applications can provide a lot of useful information to patients, helping them to access medical and pharmaceutical knowledge.

Distribution of electronic information systems in the healthcare and mobile applications allow not only to reduce government spending on the healthcare, but also to decrease the overall mortality rate of the population, reduce visits to doctors without the necessary needs and errors in prescriptions. At the same time, the introduction of medical mobile applications should be in accordance with international guidelines, in particular FDA, and the relevant state control.

\section{Conflict of interest}

No conflict of interest.

\section{References}

[1] Global Health Expenditure Data base. Available at: http://apps.who.int/nha/database/Select/Indicators/en

[2] The Future of Health care: How Mobile Medical Apps Give Control Back to Us. Available at: https:/ymedialabs.com/ future-of-healthcare

[3] Official website MOZ. Available at: http://moz.gov.ua/

[4] Examples of Pre-Market Submissions that Include MMAs Clearedor Approved by FDA. Available at: https://www.fda.gov/ MedicalDevices/DigitalHealth/MobileMedicalApplications/ucm368784.htm

[5] Official website research 2 guidance. Available at: https://research2guidance.com/325000-mobile-health-apps-availablein-2017/

[6] Official web site ABI Research. Available at: https://www.abiresearch.com/

[7] SAFEMed. Available at: https://www.usaid.gov/uk/ukraine/global-health

[8] Official web site USAID. Available at: https://www.usaid.gov/ukraine/global-health

[9] Official web site MSH. Available at: https://www.msh.org/

[10] Electronic health system: on start. Available at: http://racurs.ua/ua/1388-elektronna-systema-ohorony-zdorov-ya-na-start-uvaga-marsh

[11] Sawers, P. (2018). Kleiner Perkins and GV invest $\$ 21$ million in AI health care startup Viz.ai. Available at: https://venturebeat. com/2018/07/18/kleiner-perkins-and-gv-invest-21-million-in-ai-healthcare-startup-viz-ai/

[12] How can mobile technology improve the future of healt hcare? Available at: https://www.information-age.com/can-mobile-improve-future-healthcare-123470946/

[13] Balogh, E. P., Miller, B. T., Ball, J. R. (Eds.) (2015). Improving Diagnosis in Health Care. Washington: National Academies Press, 472. doi: http://doi.org/10.17226/21794

[14] Collier, J. (2018). 10 Best Mobile Health Apps (mHealth). Available at: https://healthtechhub.net/10-best-mobile-health-apps/

[15] Rucker,M. (2018). Mobile health devices and applications. Available at: https://www.verywellhealth.com/mobile-health-4014014

[16] Medscape. Available at: https://www.medscape.com/

[17] Epocrates. Available at: https://www.epocrates.com/

[18] Readby QxMD. Available at: https://read.qxmd.com/

[19] UpToDate. Available at: https://www.uptodate.com/home

[20] Isabel. Available at: https://www.isabelhealthcare.com/home/mobile_doc

[21] Dyna Med Mobile. Available at: https://play.google.com/store/apps/details?id=com.ebsco.dmp\&hl=en_US

[22] The New England Journal of Medicine. Available at: https://www.nejm.org/toc/nejm/medical-journal

[23] Figure 1 Medical Images. Available at: https://play.google.com/store/apps/details?id=com.figurel.android\&hl=en

[24] Virtual Practice for Doctors. Available at: https:/apps.apple.com/us/app/virtual-practice-for-doctors/id648841439

[25] My Chart. Available at: https://mychart.clevelandclinic.org/

[26] iPharmacy. Available at: https://ipharmac.co.uk/index.php/pages/privacy_policy

[27] Calculate by Qx MD. Available at: https://apps.apple.com/us/app/calculate-by- qxmd/id361811483 
[28] CardioSmart. Available at: https://www.cardiosmart.org/

[29] Doximity. Available at: https://www.doximity.com/

[30] Goo Patient. Available at: https://www.goopatient.ru/

[31] 20 useful applications for doctors and patients. Available at: https://www.imena.ua/blog/best-med-apps/

[32] Official web site eHealth. Available at: https://portal.ehealth.gov.ua/about.html

[33] Dolan, B. (2009). Physician smartphone adoption rate to reach $81 \%$ in 2012. Available at: https://www.mobihealthnews. com/4740/physician-smartphone-adoption-rate-to-reach-81-in-2012

[34] Mobile Medical Applications (2015). Guidance for Industry and Food and Drug Administration Staff. Available at: https:// www.fda.gov/downloads/MedicalDevices/DeviceRegulationandGuidance/GuidanceDocuments/UCM263366.pdf

[35] Eapen, Z. J., Peterson, E. D. (2015). Can Mobile Health Applications Facilitate Meaningful Behavior Change. Time for Answers. JAMA, 314 (12), 1236-1237. doi: http://doi.org/10.1001/jama.2015.11067

[36] Pelletier, S. G. (2012). Explosive Grow thin Health Care Apps Raises Oversight Questions. AAMC Reporte. Available at: https://www.aamc.org/newsroom/reporter/october2012/308516/health-care-apps.html

[37] Conn, J. (2012). Most-health ful apps. Mod Healthc, 42 (50), 30-32.

[38] OECD Health Data: Health expenditure and financing: Health expenditure indicators (2017). Kaiser Family Foundation analysis of data from OECD. doi: http://doi.org/10.1787/828a6dbd-en

[39] Communication from the Commission of the European Parliament, The Council, The European Economic and Social Committee, and the Committee of the Regions (2012). European Commission. eHealth Action Plan 2012-2020 - innovative healthcare for the 21st Century. Brussels. Available at: http://ec.europa.eu/information_society/newsroom/cf/dae/document. cfm?doc_id $=4188$

[40] European Commission. Green paper on mobile health ('m-health') (2014). Brussels. Available at: https://ec.europa.eu/digital-agenda/en/news/green-paper-mobile-health-mhealth

[41] Ross, J., Stevenson, F., Lau, R., Murray, E. (2016). Factors that influence the implementation of e-health: a systematic review of systematic reviews (an update). Implementation science, 11 (1), 146. doi: http://doi.org/10.1186/s13012-016-0510-7

[42] Ludwick, D., Doucette, J. (2009). Adopting electronic medical records in primary care: Lessons learned from health information systems implementation experience in seven countries. International Journal of Medical Informatics, 78 (1), 22-31. doi: http://doi.org/10.1016/j.ijmedinf.2008.06.005

[43] Liang, X., Wang, Q., Yang, X., Cao, J., Chen, J., Mo, X. et. al. (2011). Effect of mobile phone intervention for diabetes on glycaemic control: a meta-analysis. Diabetic Medicine, 28 (4), 455-463. doi: http://doi.org/10.1111/j.1464-5491.2010.03180.x

[44] Boulos, M., Wheeler, S., Tavares, C., Jones, R. (2011). How smartphones are changing the face of mobile and participatory healthcare: an overview, with example from eCAALYX. BioMedical Engineering OnLine, 10 (1), 24. doi: http://doi.org/ 10.1186/1475-925x-10-24

[45] Prgomet, M., Georgiou, A., Westbrook, J. I. (2009). The impact of mobile handheld technology on hospital physicians' work practices and patient care: a systematic review. Journal of the American Medical Informatics Association, 16 (6), $792-801$. doi: http://doi.org/10.1197/jamia.m3215

[46] Free, C., Phillips, G., Watson, L., Galli, L., Felix, L., Edwards, P. et. al. (2013). The Effectiveness of Mobile-Health Technologies to Improve Health Care Service Delivery Processes: A Systematic Review and Meta-Analysis. PLoS Medicine, 10 (1), e1001363. doi: http://doi.org/10.1371/journal.pmed.1001363

[47] What is mHealth? Available at: http://www.mhealthalliance.org/about/frequently-asked-questions

[48] New horizons for health through mobile technologies (2011). WHO. Available at: http:/www.who.int/goe/publications/goe_ mhealth_web.pdf

[49] Mobile Health Market Report 2010-2015. The Impact of Smartphone Applications on the Mobile Health Industry (2011). Available at: http://www.research2guidance.com/shop/index.php/mhealth-report

[50] Compendium of new and emerging technologies (2011). WHO, 7-30. Available at: https://apps.who.int/iris/bitstream/handle/10665/95786/WHO_HSS_EHT_DIM_11.02_eng.pdf;jsessionid=39370840291A5A01F8B823EB509E98B2?sequence=1

[51] 2013 top 10 health technology hazards (2012). ECRI. Available at: https://www.ecri.org/Resources/Whitepapers_and_reports/2013_Health_Devices_Top_10_Hazards.pdf

[52] Dolan, B. (2009). FDA may regulate iPhone health-apps/Health Apps. Available at: http://mobihealthnews.com/474/fdamay-regulate-iphone- 